УДК 621.9, 67.05

\author{
${ }^{[0000-0003-4105-7794]}$ Р. М. Крейда, асистент, \\ e-mail: r.kreida@chdtu.edu.ua \\ ${ }^{[0000-0001-9473-2285]}$ C. М. Мацепа, асистент, \\ e-mail: s_matsepa@ukr.net \\ ${ }^{[0000-0002-9223-9013]}$ В. І. Гордіснко, д.m.н., професор, \\ e-mail: valentyn.gord@gmail.com \\ [0000-0002-1836-1475] М. В. Голуб, асистент \\ e-mail: g.nikolay@ukr.net \\ Черкаський державний технологічний університет \\ б-р Шевченка, 460, 18006, м. Черкаси, Україна

\section{ОСОБЛИВОСТІ ВИГОТОВЛЕННЯ РОТОРА ДЛЯ ПОПЛАВКОВОГО ГІРОСКОПА В УМОВАХ ВИРОБНИЦТВА}

У статті представлено основні дані щзодо технологічних можсливостей приладобудівного виробниитва виготовлення деталей для механічних гіроскопів. Наведено алгоритм виготовлення та надання необхідних властивостей поверхням деталей ротора гіроскопа, які виготовлено з алюмінієвих сплавів Д16 та В95. Представлено опис послідовності виготовлення із зазначенням інструменту та обладнання, які використовувалися в ході роботи. Проведено серію експериментів для визначення режимів різання твердосплавним та алмазним інструментом. Було визначено вплив подачі, швидкості та глибини різання, які забезпечують мінімальну шорсткість сферичної поверхні ротора поплавкового гіроскопа для конкретних умов обробки. Отримані в роботі результати можуть бути використані на виробництві, при проектуванні технологічних прочесів виготовлення деталей з алюмінісвих сплавів, які мають високоточні сферичні поверхні. Окрім того, отримано додаткове підтвердження впливу радіусу округлення головної різальної кромки на шорсткість обробленої поверхні.

Ключові слова: приладобудування, гіроскоп механічний, чашка ротора, поплавковий гіроскоп, фінішна обробка, шорсткість поверхні.

Вступ. Виготовлення навігаційних приладів і систем $є$ принципово важливим і пріоритетним напрямом у сучасному приладобудуванні.

Існуючі технології дозволяють виготовити гіроскопи різних габаритів і ваги, а технологічна спадковість способу обробки визначає точність та експлуатаційний ресурс приладу.

Межа експлуатаційної надійності механічного гіроскопу [1] обумовлена вибором матеріалу, інструментом технологічного середовища його виготовлення, конструкцією [2].

Технології фінішної механічної обробки [3] мають свою специфіку та індивідуальність. До них відносять тонке алмазне точіння та полірування.

Тонке точіння забезпечує отримання поверхонь правильної геометричної форми при високій продуктивності обробки. Воно характеризується малими припусками на обробку (0.01 - 0.3 мм), малими подачами $(0.01-0.1$ мм/об) та високими швидкостями різання (300 - 700 м/хв). Така обробка в лабораторних умовах дозволяє досягти 1-2 класу точності та 8-11 класу шорсткості. Однак, в реальних виробничих умовах забезпечити показники вказаних точності та шорсткості складно, що пов'язано з рядом факторів. До таких технологічних факторів належать:

- жорсткість системи верстат-пристосування-інструмент-деталь (ВПІД);

- вибраний матеріал заготовки;

- вид різця, марка інструментального матеріалу та його форма;

- склад змащувально-охолоджуючої рідини (ЗОР) тощо.

Мета дослідження. Дослідити вплив інструменту механічного різання 3 твердосплавного матеріалу та алмазу на алюмінієві сплави Д16 та $B 95$ при формуванні сферичних поверхонь ротора поплавкового гіроскопа в умовах виробництва.

Задачі:

1. Запропонувати послідовність виготовлення ротора поплавкового гіроскопа 3 
наданням необхідних властивостей основним сферичним поверхням.

2. Визначити оптимальні режими на чорновій та чистовій стадіях обробки, що приводять до мінімальної шорсткості на сферичних поверхнях.

Аналіз останніх досліджень. Незважаючи на кількість робіт щодо оптимізації режимів і процесів обробки, вдосконалення технологічних методів для підвищення експлуатаційних якостей продукції залишається актуальною задачею. Так, у роботі [4] автори застосовують метод Тагучі для пошуку оптимальних значень подачі, швидкості та глибини різання з точки зору максимальної продуктивності при мінімальній шорсткості поверхні. Попок та ін. [5] у своїй роботі розглянули схеми зняття припуску при точінні сферичних та конічних поверхонь. Також вони визначили умови обробки та геометрію інструменту при яких забезпечується мінімальне тепловиділення. В роботі [6] автори дослідили вплив вставок різної форми в державки розточного токарного різця на шорсткість обробленої поверхні. Степанов у своїй роботі [7] відмітив, що домінуючий вплив на формування шорсткості поверхні має радіус округлення головної різальної кромки, подача і амплітуда радіальних коливань між інструментом і заготовкою. Так, збільшення радіуса округлення 313 до 50 мкм, призводить до збільшення параметра Ra 3 0,18 до 0,55 мкм. В роботі [8] досліджено співвідношення між шорсткістю поверхні, умовами обробки та силою різання. Відмічається, що шорсткість стає нижчою при зменшенні подачі та глибини різання і збільшенні швидкості різання і радіусу вершинки різця. Мається на увазі, що шорсткість поверхні можливо прогнозувати за силами різання, які виникають в процесі точіння алюмінієвих сплавів.

На практиці, при визначенні режимів різання для забезпечення необхідної шорсткості поверхні, технологи часто обмежуються розрахунковим значенням висоти залишкових гребінців, які залежать від форми різця і подачі [9]. Такий метод дає приблизні результати і може використовуватись лише для попередніх розрахунків. Для більш точного прогнозування шорсткості користуються емпіричними моделями, які залежать від багатьох технологічних факторів. Однак для їх визначення необхідно проводити велику кількість експериментальних робіт.

(C) Р. М. Крейда, С. М. Мацепа, В. І. Гордієнко, М. В. Голуб, 2020 DOI: $10.24025 / 2306-4412.2 .2020 .198240$
Таким чином, дослідження впливу інструментального матеріалу на матеріал заготовки при конкретних умовах обробки, є актуальною науковою задачею.

Виклад основного матеріалу. Для визначення впливу технології обробки та режимів різання на якість сферичних поверхонь ротора поплавкового гіроскопа було проведено ряд експериментів, які проводились на високопрецизійному токарному верстаті 842Mi швейцарської фірми SCHAUBLIN MACHINES SA. В якості різців для точіння сфер використовувались державки A16M SVLCR07 компанії DENITOOL (Швейцарія). Під час обробки використовувалась 3ОР марки Blasocut 2000 Universal (Швейцарія). Робота виконувалась в послідовності, представленій на рис. 1.

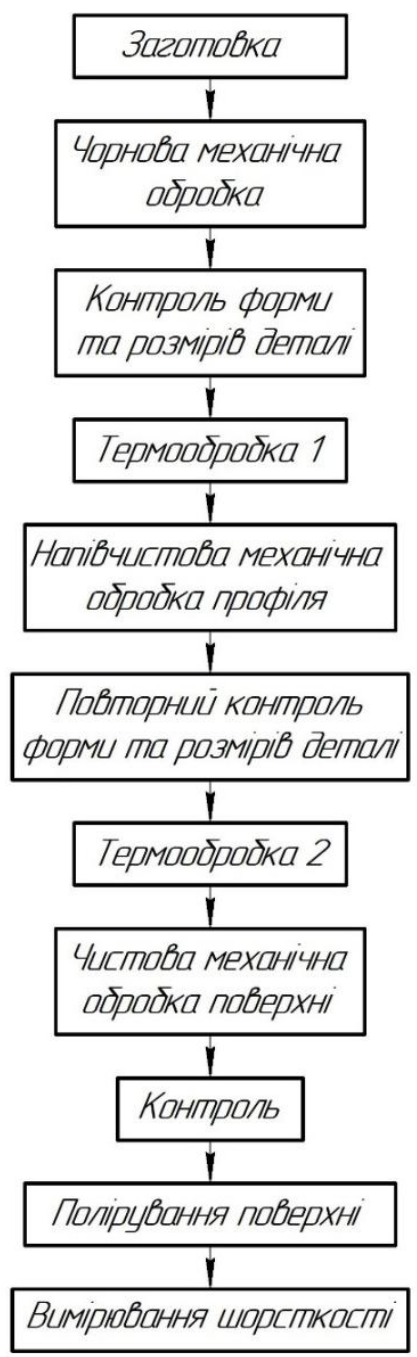

Рисунок 1 - Спрощена схема виготовлення ротора з алюмінісвих сплавів Д16 та В95 за заданою шорсткістю 
Оброблялись заготовки круглого сортового прокату, порізані на мірні частини. Деталі оброблялись методом послідовного приближення профілю заготовки до дійсних розмірів деталі 3 міжопераційною термообробкою, яка проводилась згідно з ГОСТ 17535-77 за режимами Т1-Т3. Перед механічною обробкою заготовки зі сплавів Д16 та В95 піддавались гартуванню до твердості 142-148 HV та 180-183 HV відповідно для покращення їх механічних властивостей. Зміна форми заготовок відбувалася механічним різанням (різцями) чорновим та чистовим способами.

При чорновій обробці використовувався розточний різець 3 пластинкою (шифр VCGT 070204-25) 3 твердого сплаву 3 покриттям DX30 (рис. 2), компанії DENITOOL (Швейцарія). Контроль форми та розмірів проводився універсальними вимірювальними приладами. При напівчистовій та чистовій механічній обробці використовувався розточний різець із закріпленою пластинкою (шифр VCGW 070202 CB-P) з розміщеним на кінці алмазним зерном CVD (рис. 3), фірми DTS GmbH (Hiмеччина). Під час обробки використовувалась функція контролю швидкості різання на поверхні G96 з обмеженням максимальної частоти обертання до 4000 об/хв. Вибір оптимальних режимів різання проводився з наступних діапазонів: швидкість різання $\mathrm{V}_{\text {різ }}=150-600 \mathrm{M} / \mathrm{xв}$, глибина різання $\mathrm{t}=0.01-0.05$ мм, подача $\mathrm{S}$ приймалась 0.01-0.07 мм/об. Після напівчистової та чистової механічної обробки контроль форми та розмірів проводився на координатно-вимірювальній машині Axiom too HS, компанії Aberlink (Великобританія). Полірування сферичної поверхні проводилось вручну (без зміни форми поверхні) за допомогою пасти ГОИ №3 ТУ 6-18-36-85, матеріал полірувальника: войлок, бязь технічна. Припуск на полірування складав менше 1 мкм.

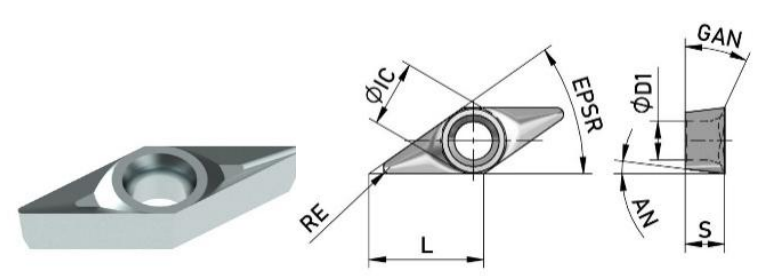

Рисунок 2 - Пластинка VCGT 070204-25 DX30 [10]

RE - 0.4 мм, IC - 3.97 мм, L - 6.92 мм, EPSR - 35.0 $, \mathrm{AN}-7.0^{\circ}, \mathrm{S}-2.38$ мм, D1 - 2.3 мм, GAN $-25.0^{\circ}$

(C) Р. М. Крейда, С. М. Мацепа, В. І. Гордієнко, М. В. Голуб, 2020 DOI: $10.24025 / 2306-4412.2 .2020 .198240$

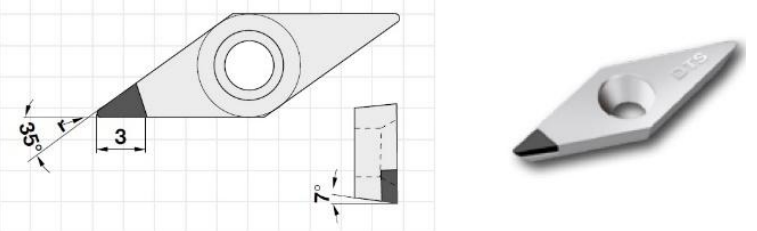

Рисунок 3 - Пластинка VCGW 070202 CB-P CVD [11]

Після напівчистової та чистової механічної обробки, а також після полірування проводилося вимірювання поздовжньої шорсткості в трьох перерізах. Для цього використовувався портативний вимірювач шорсткості моделі Time 3221 (рис. 4), компанії TIME Group Inc. (KHP).

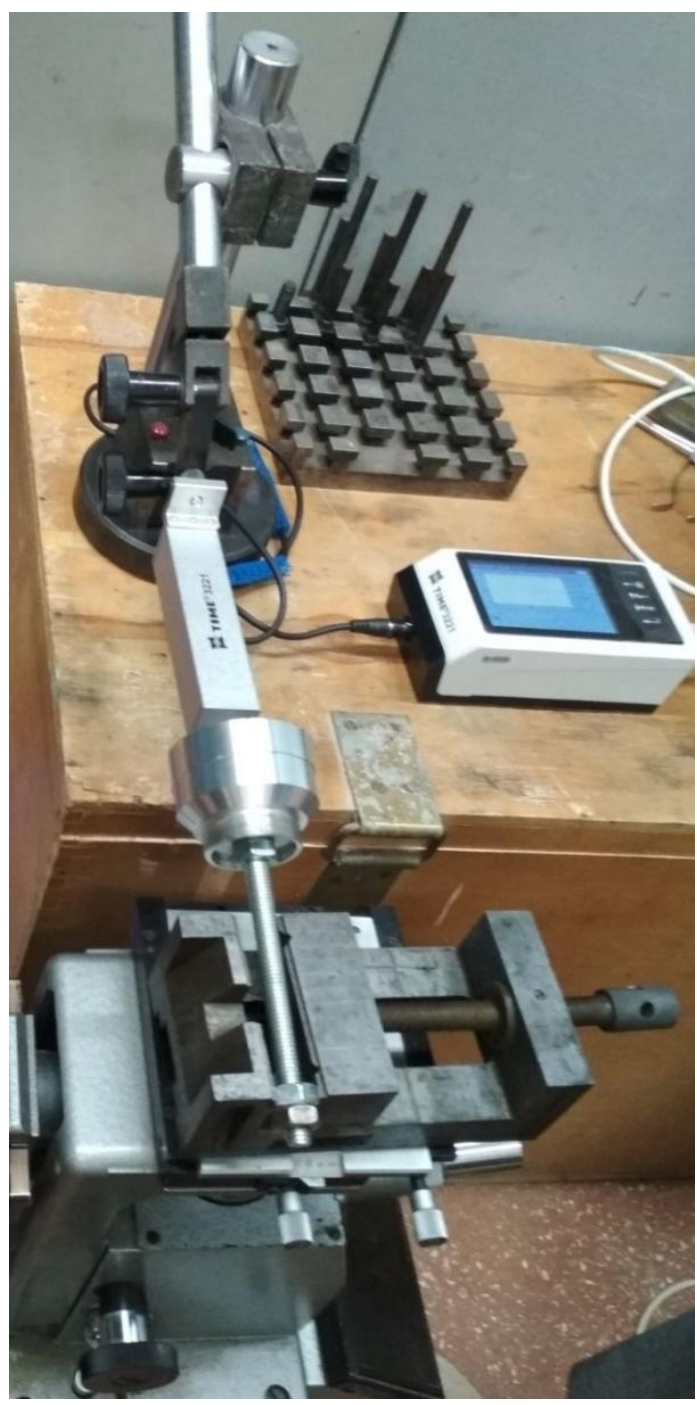

Рисунок 4 - Портативний вимірювач шорсткості Time 3221 
Матеріал вимірювального пера - алмазна голка 3 кутом при вершині $90^{\circ}$ і радіусом 5 мкм. Для вимірювання шорсткості була вибрана довжина оцінки 0.8 мм зі стандартного переліку довжин, які запропоновані розробником. На вибраній довжині щуп рухався 3 постійною швидкістю $0.5 \mathrm{~mm} / \mathrm{c}$.

Для вимірювання шорсткості профілометр закріплявся на стояк для зручності регулювання кута нахилу приладу. Деталь, в свою чергу, закріплялася на шпильку, затиснуту в лещатах. Останні установлювались на інструментальний мікроскоп для мікрометричного регулювання положення дослідного зразка відносно вимірювального приладу. Плавним регулюванням вертикального положення деталі щуп профілометра торкався поверхні, що досліджувалась.

На рисунку 5 показана залежність шорсткості від подачі отримана за результатами теоретичних розрахунків та за результатами вимірювання шорсткості сферичної поверхні 3 матеріалу Д16, обробленої при постійній швидкості різання $\mathrm{V}_{\mathrm{piz}}=300 \mathrm{~m} / \mathrm{xв}$, глибині різання $\mathrm{t}=0,25$ мм, вильоті різця $\mathrm{L}=45$ мм. Подача 30 в відбувалась внутрішньо (через різець). Теоретичний розрахунок шорсткості проводився за формулою Чебишева:

$$
\mathrm{R}_{\mathrm{z}}=\frac{\mathrm{s}^{2}}{8 \mathrm{r}}
$$

де $\mathrm{R}_{\mathrm{z}}$ - висота нерівності профіля по десяти точках, мкм;

$\mathrm{S}$ - подача, мм/об;

$\mathrm{r}$-радіус вершинки різця.

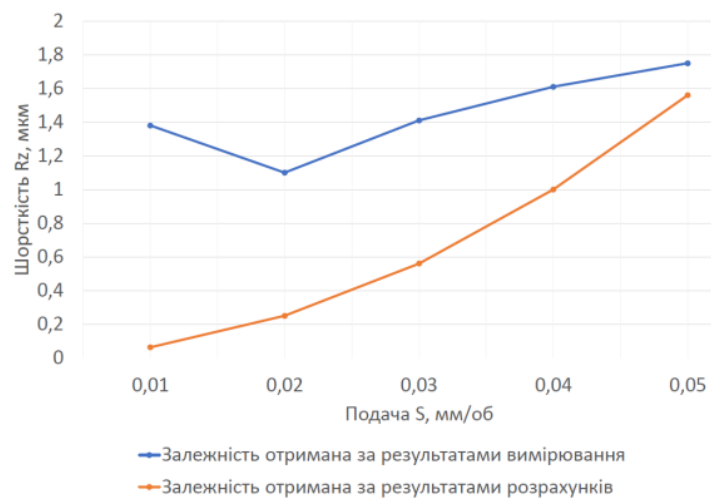

Рисунок 5 - Залежність шорсткості від подачі

Вимірювання шорсткості сферичної поверхні, обробленої алмазним інструментом при тонкому точінні на різних режимах, показали значний вплив подачі та незначний вплив швидкості та глибини різання. При (C) Р. М. Крейда, С. М. Мацепа, В. І. Гордієнко, М. В. Голуб, 2020 DOI: $10.24025 / 2306-4412.2 .2020 .198240$ цьому висота мікронерівності $\mathrm{R}_{\mathrm{z}}$ зменшувалася при зменшенні подачі до $\mathrm{S}=0.02$ мм/об. Подальше ж зменшення подачі призводило до погіршення якості поверхні. Це пояснюється відсутністю стабільного процесу різання через досягнення критичної товщини шару металу, що зрізається. Наявність радіусу округлення головної різальної кромки призводить до підминання металу (надирів), тобто погіршення шорсткості поверхні.

Виходячи 3 технологічних можливостей підприємства за методикою, запропонованою в [12], була розроблена блок-схема виготовлення ротора, представлена на рис. 6 .

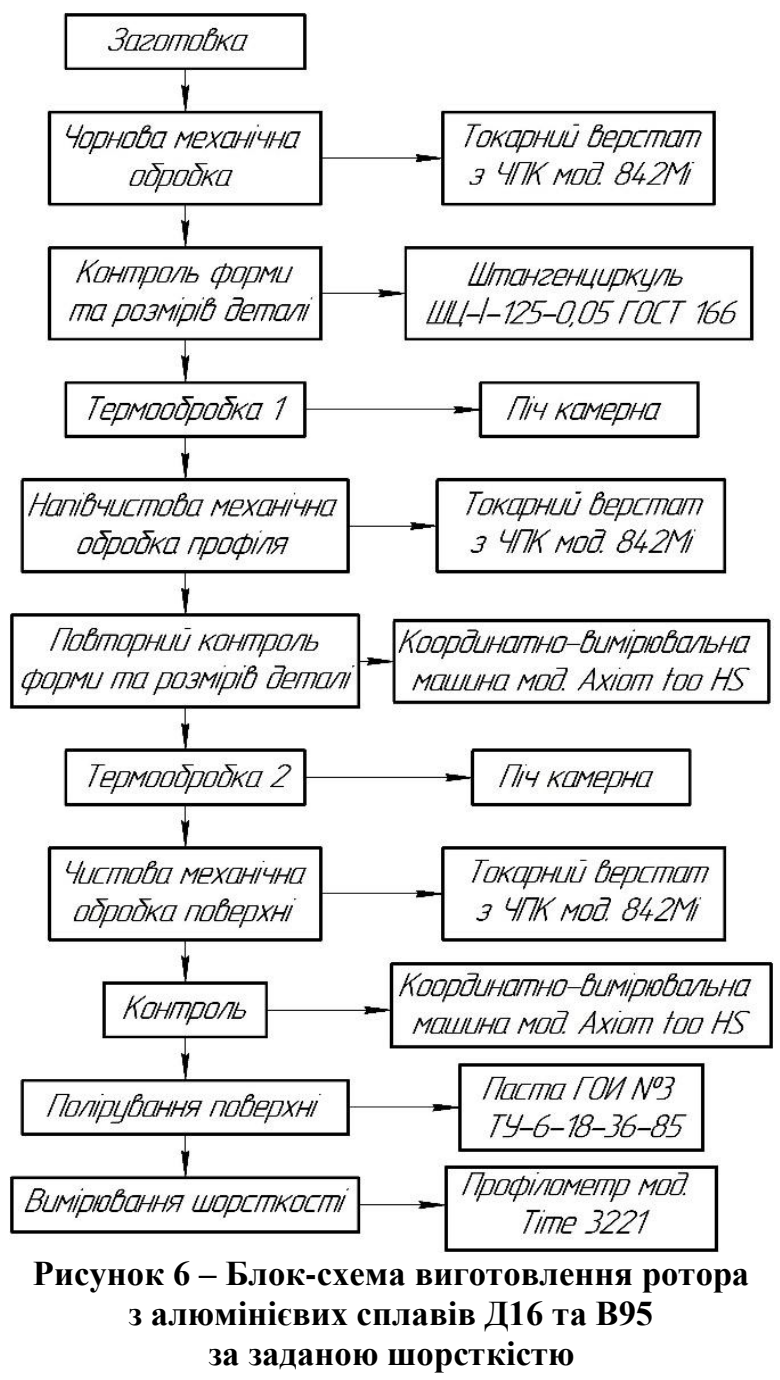

За результатами експериментальних досліджень було зроблено висновки щодо оптимальних режимів обробки деталі на кожній операції. Їх значення, результати вимірювання шорсткості та фото сферичної поверхні представлені в таблиці 1. 
Таблиця 1 - Оптимальні режими обробки, результати вимірювання шорсткості та фото поверхні

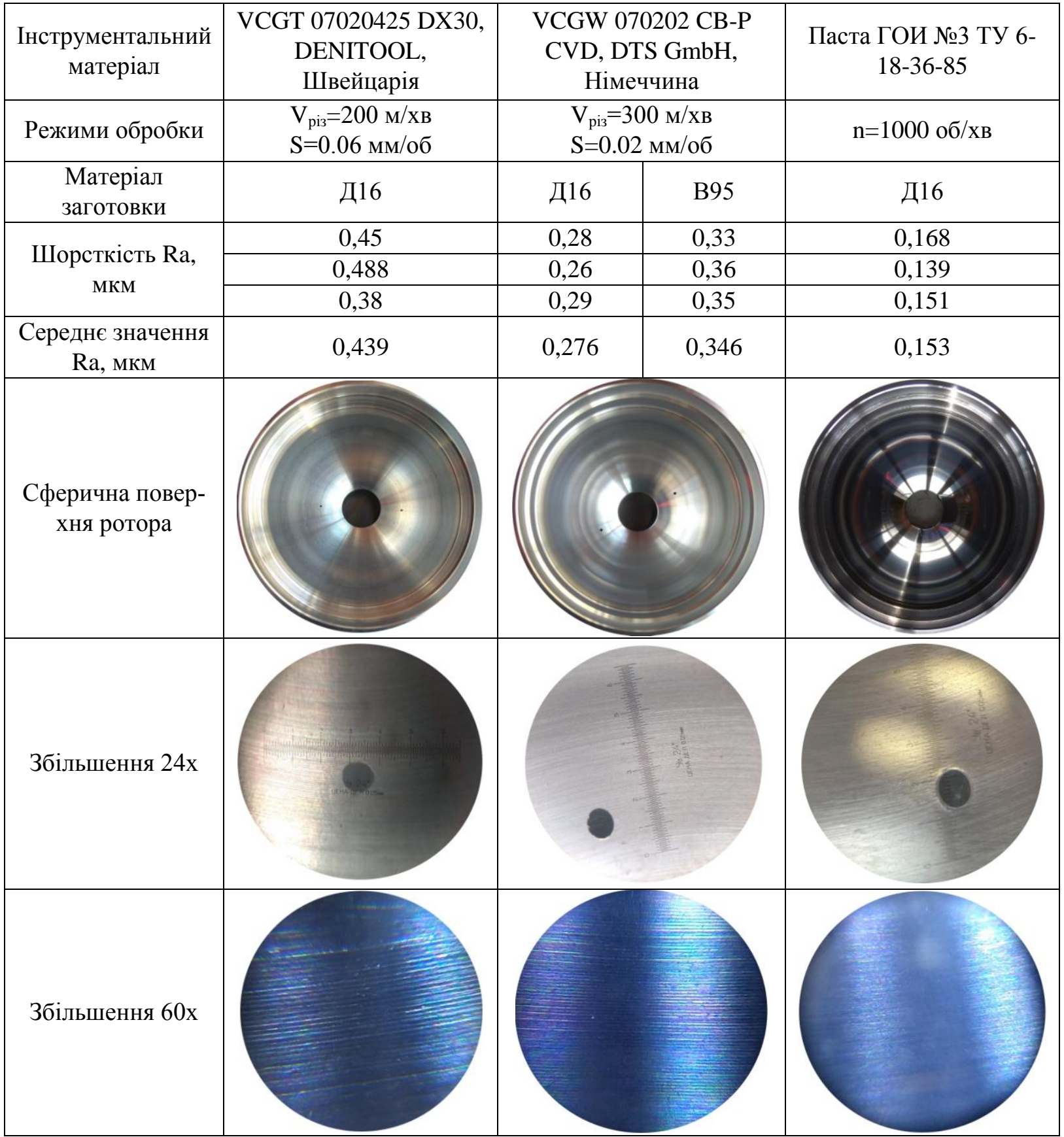

\section{Висновки:}

1. Розроблено та адаптовано до умов виробництва алгоритм і технологічну послідовність виготовлення ротора поплавкового гіроскопа.

2. Досліджено та визначено режими обробки при точінні сферичних поверхонь ротора із алюмінієвих сплавів твердосплавним інструментом, яким досягається шорсткість поверхні $\mathrm{Ra}=0,439$ мкм, при точінні Д16, (C) Р. М. Крейда, С. М. Мацепа, В. І. Гордієнко, М. В. Голуб, 2020 DOI: 10.24025/2306-4412.2.2020.198240 та алмазним інструментом, шорсткість $\mathrm{Ra}=0,276$ мкм, при точінні Д16 та $\mathrm{Ra}=0,346$ мкм, при точінні В95.

3. Вимірювання шорсткості сферичної поверхні на матеріалі Д16 обробленій пластинкою із синтетичного алмаза VCGW 070202 CB-P CVD показали, що висота мікронерівності зменшується зі зменшенням подачі до 0,02 мм/об. 


\section{Список використаних джерел}

[1] В. В. Аврутов, и Н. И. Бурау, Надежность и диагностика приборов и систем: учеб. пособие. Киев: НТУУ «КПИ», 2014.

[2] К. П. Андрейченко, Динамика поплавковых гироскопов и акселерометров. Москва: Машиностроение, 1987.

[3] Ф. В. Новіков, та І. О. Рябенков, Фінішна обробка деталей різанням: монографія. Харків: ХНЕУ ім. С. Кузнеця, 2016.

[4] M. K. Singh, D. Chauhan, M. K. Gupta, and A. Diwedi, "Optimization of process parameters of aluminum alloy (Al-6082 T-6) machined on $\mathrm{CNC}$ lathe machine for low surface roughness", Journal of Material Sciences \& Engineering, 4, p. 202, 2015.

[5] Н. Н. Попок, Р. С. Хмельницкий, и В. С. Анисимов, "Особенности обработки сферических и конических поверхностей деталей на токарных станках с ЧПУ", Вестник Витебского государственного технологического университета, № 1 (32), c. 109-121, 2017.

[6] В. А. Рогов, и П. С. Белов, "Исследование влияния режимов резания при тонком точении на качество поверхности", Вестник РУДН. Серия: Инженерные исследования, № 4, 2012.

[7] С. Н. Степанов, "Обеспечение шероховатости обработанной поверхности при тонком алмазном точении алюминиевых сплавов", автореф. дис. канд. техн. наук: спец. 05.02.08 "Технология машиностроения", Санкт-Петербург, 1994.

[8] A. Chaijareenont, and S. Tangjitsitcharoen, "Monitoring of surface roughness in aluminium turning process", IOP Conf. Series: Materials Science and Engineering, 303, 2018.

[9] В. К. Нгуен, "Повышение эффективности точения фасонных деталей", дис. канд. техн. наук: спец. 05.02.08 "Технология машиностроения", Тула, 2013.

[10] https://store.denitool.com/store/vcgt070204-25-dx30/

[11] https://diamond-toolingsystems.com/wpcontent/uploads/Katalog-PKD-PCD-CVDWSPL-WEB_2018.pdf?pdf=katalog-pkdpcd-cvd-wspl-web_2018

[12] А. М. Дальский,

А. Г. Косилова, Р. К. Мещеряков, и А. Г. Суслов, Сnpaвочник технолога-машиностроителя: в 2

(C) Р. М. Крейда, С. М. Мацепа, В. І. Гордієнко, М. В. Голуб, 2020 DOI: $10.24025 / 2306-4412.2 .2020 .198240$ т. Т. 1. 5-е изд., испр. Москва: Машиностроение-1, 2003.

\section{References}

[1] V. V. Avrutov, and N. I. Burau, Reliability and diagnostics of devices and systems: textbook. Kiev: NTUU "KPI", 2014 [in Russian].

[2] K. P. Andrejchenko, Dynamics of float gyroscopes and accelerometers. Moscow: Mashinostroenie, 1987 [in Russian].

[3] F. V. Novikov, and I. O. Ryabenkov, Finishing processing of details by cutting: monograph. Kharkiv: KhNEU im. S. Kuznet-sya, 2016 [in Ukrainian].

[4] M. K. Singh, D. Chauhan, M. K. Gupta, and A. Diwedi, "Optimization of process parameters of aluminum alloy (Al-6082 T-6) machined on $\mathrm{CNC}$ lathe machine for low surface roughness", Journal of Material Sciences \& Engineering, 4, p. 202, 2015.

[5] N. N. Popok, R. C. Khmelnitsky, and V.S. Anisimov, "Features of processing of spherical and conical parts surfaces on CNC lathes", Vestnik Vitebskogo gosudarstvennogo tehnologicheskogo universiteta, no. 1 (32), pp. 109-121, 2017 [in Russian].

[6] V. A. Rogov, and P. S. Belov, "Investigation of the influence of cutting conditions during thin turning on surface quality", Vestnik RUDN, Seriya: Inzhenernyie issledovaniya, no. 4, 2012 [in Russian].

[7] S. N. Stepanov, "Providing the roughness of machined surface with thin diamond turning of aluminum alloys", Ph.D. thesis: spec. 05.02.08 "Mechanical engineering technology", St. Petersburg, 1994 [in Russian].

[8] A. Chaijareenont, and S. Tangjitsitcharoen, "Monitoring of surface roughness in aluminium turning process", IOP Conf. Series: Materials Science and Engineering, 303, 2018.

[9] V. K. Nguyen, "Improving the efficiency of turning shaped parts", Ph.D. thesis: spec. 05.02.08 "Mechanical engineering technology", Tula, 2013 [in Russian].

[10] https://store.denitool.com/store/vcgt070204-25-dx30/

[11] https://diamond-toolingsystems.com/wpcontent/uploads/Katalog-PKD-PCD-CVDWSPL-WEB_2018.pdf?pdf=katalog-pkdpcd-cvd-wspl-web_2018 
[12] A. M. Dalsky, A. G. Kosilova, R. K. Meshcheryakov, and A. G. Suslov, Handbook of technological engineer: in 2 vols. Vol. 1. 5th ed., cor. Moscow: Mashinostroenie-1, 2003

[in Russian].

R. M. Kreida, assistant lecturer,

e-mail: r.kreida@chdtu.edu.ua

S. M. Matsepa, assistant lecturer, e-mail: s_matsepa@ukr.net

V. I. Gordienko, D.Tech.Sc., professor, e-mail: valentyn.gord@gmail.com

M. V. Golub, assistant lecturer e-mail: g.nikolay@ukr.net

Cherkasy State Technological University, Shevchenko blvd, 460, Cherkasy, 18006, Ukraine

\section{PECULIARITIES OF MANUFACTURE OF A ROTOR FOR FLOAT GYROSCOPE IN THE PRODUCTION CONDITIONS}

The problem of ensuring the performance of high-precision parts of navigation systems, while forming their surfaces by turning, has become extremely urgent today. The use of wide-ranging numerically controlled machine tools for precision spherical surfaces is promising, provided the required shape accuracy and roughness are required. Practical experience with the use of synthetic single-crystal interchangeable diamond plates has shown the need to find technological solutions related to reducing the surface roughness under certain conditions. The article presents the basic data on the technological capabilities of instrument production of manufacturing the parts for mechanical gyroscopes. The algorithm and technological sequence of manufacturing and providing the necessary properties to the surfaces of gyroscope rotor parts made of D16 and B95 aluminum alloys are presented. A description of the manufacturing sequence is given, indicating the tools and equipment used during the operation. A detailed description of geometric parameters of the variable plates with the indication of manufacturers is given. A series of experiments has been conducted to determine the cutting modes by carbide and diamond tools. The influence of flow, speed and depth of cutting have been determined to ensure the minimum roughness of spherical surface of float gyroscope rotor for specific processing conditions. The results of the roughness measurements after polishing the surface obtained with diamond sharpening are presented. The results obtained can be used in the production, in the design of technological processes for the manufacture of parts made of aluminum alloys which have high-precision spherical surfaces. In addition, additional confirmation of the influence of the radius of rounding of the main cutting edge on the roughness of the machined surface has been obtained.

Keywords: instrumentation, mechanical gyroscope, rotor cup, float gyroscope, finishing, surface roughness.

Стаття надійшла 01.02.2020

Прийнято 20.02.2020 